\title{
r

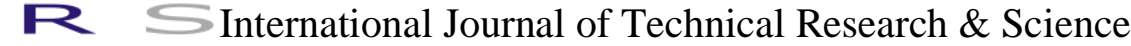 AN TRUST MODEL FOR INCREASING SECURITY IN CLOUD COMPUTING
}

\author{
Naveen Choubisa ${ }^{1}$, Jitendra Singh ${ }^{2}$ \\ E-Mail Id: chauhan.jitendra@live.com \\ Research Scholar ${ }^{1}$, Associate Professor ${ }^{2}$, Aravali Institute of Technical Studies, Udaipur (Rajasthan), India
}

\begin{abstract}
As security and privacy of the cloud and data are usually handled by the service providers, the data owners may not even be fully aware of the underlying security challenges and solutions. Substantial scale organizations and utilization of distributed computing in industry is went with and in a similar time hampered by concerns in regards to security of information took care of by Distributed computing suppliers. One of the outcomes of the moving information preparing and capacity organization premises is that associations have less control over their framework. Subsequently, cloud benefit (CS) customers must assume that the CS supplier can Shield their information and Framework from both outside and inside assaults.

Having the instruments to perform such verifications before the dispatch of the VM occasion enables the CS customers to choose in runtime whether certain information ought to be put away or estimations ought to be made on the VM occurrence offered by the CS supplier.

This theory consolidates three components trusted computing, virtualization, Innovation and distributed computing stages to address issues of trust and security in broad daylight distributed computing situations of the three components virtualization, innovation has had the longest development and is a foundation for the acknowledgment of distributed computing. Trusted computing is the current industry activity that accepts to execute the base of trust in an equipment part, the put stock is in stage module. The activity has been formalized in an arrangement of details and is at present at rendition distributed computing stages pool virtualized computing, stockpiling and system assets keeping in mind the end goal to serve countless that utilization in a multi- inhabitant multiplexing model to on request self benefit over wide system. Open source distributed computing stages are, like put stock in computing, a genuinely late innovation in dynamic advancement.
\end{abstract}

Keywords: Virtual Machine, Cloud Computing, Security

\section{INTRODUCTION}

Functionality clients will in popular stay far from a selected innovation at some factor trouble they enjoy suspicious about its ability to comply to their protection requests. Such misplaced agree with ought to appear in vital registering degrees, specifically cloud, project, and versatile ranges. on this proposition, we advise to enhance be given as proper with inside the ones stages by means of (i) enhancing their safety additives, and (ii) giving their clients guarantees that these structures are set up. Nowadays, figuring improvement soaks each piece of current-day society. Over the span of the cutting-edge 50 years, mainly for the motive that method of the pc and the internet, bewildering enhancements in registering development had been energetically grasped by means of society. A huge collection of hardware, programming, and corporations have notably affected the lives of human beings and relationship in a fullsize scope of human, from beguilement (e.g., entertainments) to assignment-critical assignments (e.g., commercial enterprise, restorative administrations, and assets). This augmentation of improvement grows to be, all topics taken into consideration, viable in view of the snare of expect that has been labored amongst customers and companies of development. for the motive that customers do now not normally have prepare studying of the development internals, their conviction approximately a specific factor have to be set up on take delivery of as genuine $[1,2]$.

Clients consider is labored through the dynamic social affair of verification for a provided improvement, to the point in which the perils of failure to meet the customer's desires ended up being notably appealing [3]. A conventional example of this approach is net putting aside extra cash. On-line placing aside some cash ended up normal in view of several duties in fortifying surrender-clients keep in thoughts. The ones duties consolidated the headway of protection gadgets (e.g., cryptography, threatening to ailment, software safety, protection traditions) and the quantity of client incidents thru banks and protection workplaces in case of protection bursts (e.g., phishing, misrepresentation). Data has in like way exhibited that customers keep in mind is sensitive and can be viably damaged down due to misinterpreted actions via using the development vendors or through the containments of the improvement itself. scenes in which facebook and instagram have made their protection strategies increasingly more indulgent had been in reality gotten with the useful resource of the all inclusive community and the omnipresence of these corporations have end up speedy affected. Correspondingly, the loss of customers' statistics by way of the use of using the usage of amazon s3 addressed a large hit to the authenticity of dispersed registering, to preserve a stoppage within the amassing of improvement, its miles then essential that the agencies of development hold being resolved in preserving up their clients remember [4-6]. 


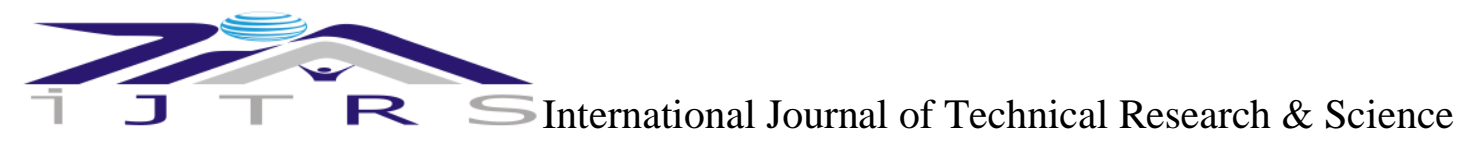

\subsection{Cloud Systems}

Cloud stages are one smooth circumstance in which constructing get hold of as right with is as important as it is making an attempt. Circulated processing takes after a redistributing model in which cloud organizations adjust their datacenter shape thru giving cloud organizations. Customers may also want to then have the capability to promote off statistics encouraging and computation to the cloud through identifying to shop for the advantages exhausted, for the cause that clients pay for the ones cloud agencies, they envision that their data is probably controlled sincerely within the cloud. As proper scenes have showed up, dissatisfaction with the useful resource of the cloud providers to manipulate customers' records, e.g., with the resource of spilling or dropping facts, can be unfavorable for clients and significantly impact the recognition of cloud corporations. Along the ones lines, cloud carriers enterprise to create client's take into account via making their structures honest, as an instance, anchoring their premises, selecting expert architects, and turning into in with excellent practices. Regardless, but the extraordinary undertakings of the cloud companies, customers have imparted more than one stresses over the cloud. Starting, a nonattendance of straightforwardness is unavoidable. Thru and big due to protection and organization concerns, cloud businesses have a tendency to be covered approximately the internals of their cloud establishments. This nonappearance of straightforwardness brings one-of-a-kind inquiries up in customers' cerebrums. clients do not have the foggiest perception, as an example, that could get to the facts, who manages the cloud shape, what writing pc programs is without a doubt supplied, how their facts is getting used, or on which territories (and wards) the data may be secured. 2nd, modern-day-day cloud stages are slanted to reduce to rubble dangers [8].The cloud administrators, who're responsible for providing, organizing, and jogging this item, ought to alter the lead of a cloud benefit with the beneficial resource of reinstalling, reconfiguring, or controlling the give up result of the cloud centers. Proper at the equal time as completed via a reckless or a malicious cloud regulator, such activities need to advantage the spillage, pollutants, or loss of consumer facts. Ultimately, this nonappearance of confirmation approximately the direct of cloud corporations prevents numerous relationships from the use of the cloud for protection sensitive assignments [5, 6].

\section{IMPROVING TRUST IN MODERN COMPUTING PLATFORMS}

$>$ Positioned into impact the protection residences required with the beneficial useful resource of the customers. Anyhow, we intend to beautify the confirmation of customers' records and estimations through enhancing the protection of the processing tiers. The unique protection homes to be finished and the peril display beneath which they ought to be located out are put together particular. in the cloud placing, we intend to preserve cloud directors from evaluating or interfering with counts taking region in customers' virtual machines, in the mission scenario, we need to allow administrators to preserve up the going for walks systems without changing off the mystery and uprightness of information observed and organized in customer debts. In adaptable conditions, we are able to probably make frameworks for confirmation of the bendy packages. Within the event of safety breaks that could exchange off the entire OS $[14,16]$.

$>$ Deliver customers guarantees that the favored protection residences are being maintained. $2 \mathrm{~d}$, in mild of the truth that a notable a part of the time customers do not have strength over the registering stages, paying little thoughts to whether or not or now not a purpose installation actualizes their pined for safety homes, clients do no longer have the terrific approach to get some answers concerning the extent U.S. of America and cannot inform paying little heed to whether or not or now not it has a unethical to be depended on. Because of this, it's far vital to interface this hollow via giving customers guarantees regarding the affiliation of the devices that approve the pined for protection homes, to offer such ensures we rent strategies: depended on in processing system, which offers online factors to a ways off approval of a phase's state, and region stock in certifiers, which provide

separated insistence administrations [17-19].

\subsection{Cloud Computing Carrier Models}

Dispersed processing consists of 3 critical commercial enterprise commercial enterprise organization models whereupon the furnished cloud advantage relies upon the businesses furnished at a larger sum rely upon the agencies supplied on the critical dimensions of this employer show[1,2].

\subsection{Infrastructure as a Service (IaaS)}

Layer of the appropriated processing organization show off in which cloud authority facilities supply searching after, gathering, memory and furthermore arranging benefits for customers and is for the most element in a virtualized place $[6,7]$. 


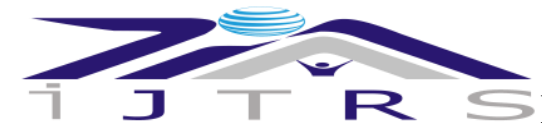

2.3 Platform as a Service (PaaS)

International Journal of Technical Research \& Science

Layer of the disseminated processing corporation show in which cloud pro establishments supply clients (usually

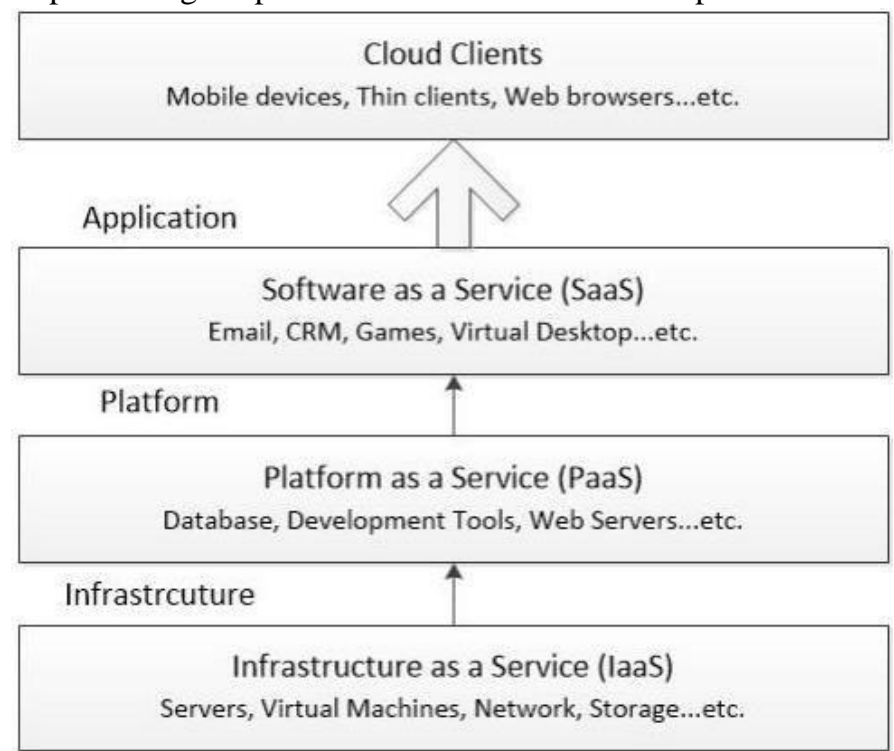

designs) with the ordinary degrees to be organized for sending and coping with packages using programming vernaculars or mechanical assemblies which may be supplied in the cloud without start to complete information of the hid installation order situation [2,5].

\subsection{Software as a Service (SaaS)}

Layer of the circulated registering business enterprise display wherein cloud authority corporations deliver clients the restriction of executing programs without a getting to know of the enhancement degrees or the set up order scenario being used to have those programs.

\section{SIMULATION AND QUIT RESULT}

The execution and leisure of the proposed calculation is finished the usage of Dot internet and Java Script. Dab net Framework (articulated spot internet) is a product framework made through Microsoft that runs essentially on Microsoft windows. It joins a big splendor library called Framework beauty Library (FCL) and offers tongue interoperability (every vernacular may be use created code in unique unmistakable lingos) transversely over to the several programming tongues. obligations created for

.internet Framework carry out in a product situation (as separated to device scenario), referred to as not unusual Language Runtime (CLR), an software digital machine that offers benefits for example, protection, memory the executives, and exclusion handling. FCL and commonplace Language Run time to acquire address .net Framework [7].

FCL offers use interface, data get to, database accessibility, cryptography, internet software headway, numeric calculations, and tool correspondences. software program application program engineers deliver turning into a member of that allows you to application their very private deliver code with. internet Framework and one of a kind differing libraries. .net Framework is supposed for use with the assist of maximum novel programs conveyed for home domestic home windows diploma. Microsoft furthermore makes a planned improvement state of affairs, as it have been, for. internet programming called seen Studio.

JavaScript is a dynamic computer programming dialect [3] it's miles most usually used as a phase of internet browsers, whose utilization allow patron factor contents to interface with the purchaser, control this device, provide non simultaneously, and trade the document content material fabric that is appeared. it is in like manner used as a chunk of the server-thing device programming with runtime conditions such as Node.js, enjoyment enhancement and the transable and art work vicinity packages advent.

JavaScript is organized as a version based totally scripting language with dynamic composing and 5 movie star capacities. This mixture of additives makes it a multi-mindset vernacular, supporting object placed, important, and superb programming styles. No matter some naming, syntactic, and massive library tantamount inclinations, JavaScript and Java are all round immaterial and want to the extra a part of the semantics. The etymological shape of JavaScript is definitely gotten from $\mathrm{C}$, at the same time as the semantics and device are impacted without a different character and Scheme programming tongues [39]. This combination of fragments makes it a multi-angle lingo, supporting problem masterminded, vital, and accommodating programming patterns. But a few naming, syntactic, and preferred library identical characteristics, JavaScript and Java are commonly unimportant and want to the extra a DOI Number: https://doi.org/10.30780/IJTRS.V06.I04.002

pg. 8 


\section{J $\mathbb{R} \leqq$ International Journal of Technical Research \& Science}

part of the semantics. The etymological form of JavaScript is surely gotten from C, while the semantics and device are impacted without a completely unique individual and Scheme programming tongues [4].

JavaScript is likewise carried out as a bit of the affectation that aren't digital, as an instance, PDF evaluations, internet web page online-particular duties, and works area gadgets. More the front line and snappier JavaScript digital machines (VMs) and stages counting on them have moreover extended the notoriety of JavaScript for serverfactor internet programs. on the consumer issue, JavaScript has been customarily executed as a translated dialect, besides later browsers perform in the nick of time accumulation [5].

\section{BASE RESULTS}

\subsection{Home page}

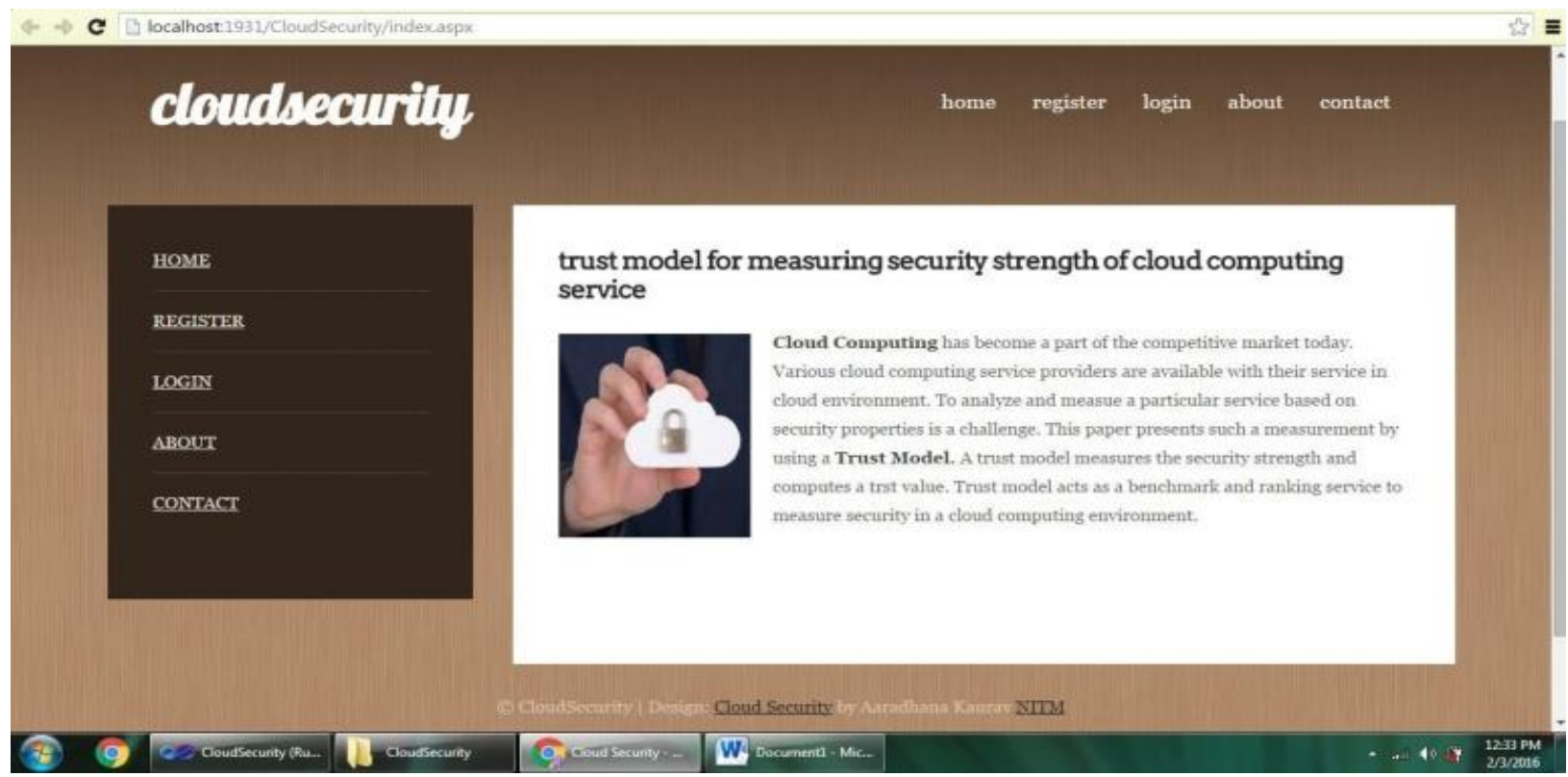

Fig. 4.1 Created Home page

This image shows the home page of cloud security in this home page menu is designed and have no of fields Home, Registration, Login, About, Contact. You choose any type of filed according to requirement.

\subsection{Registration Page}

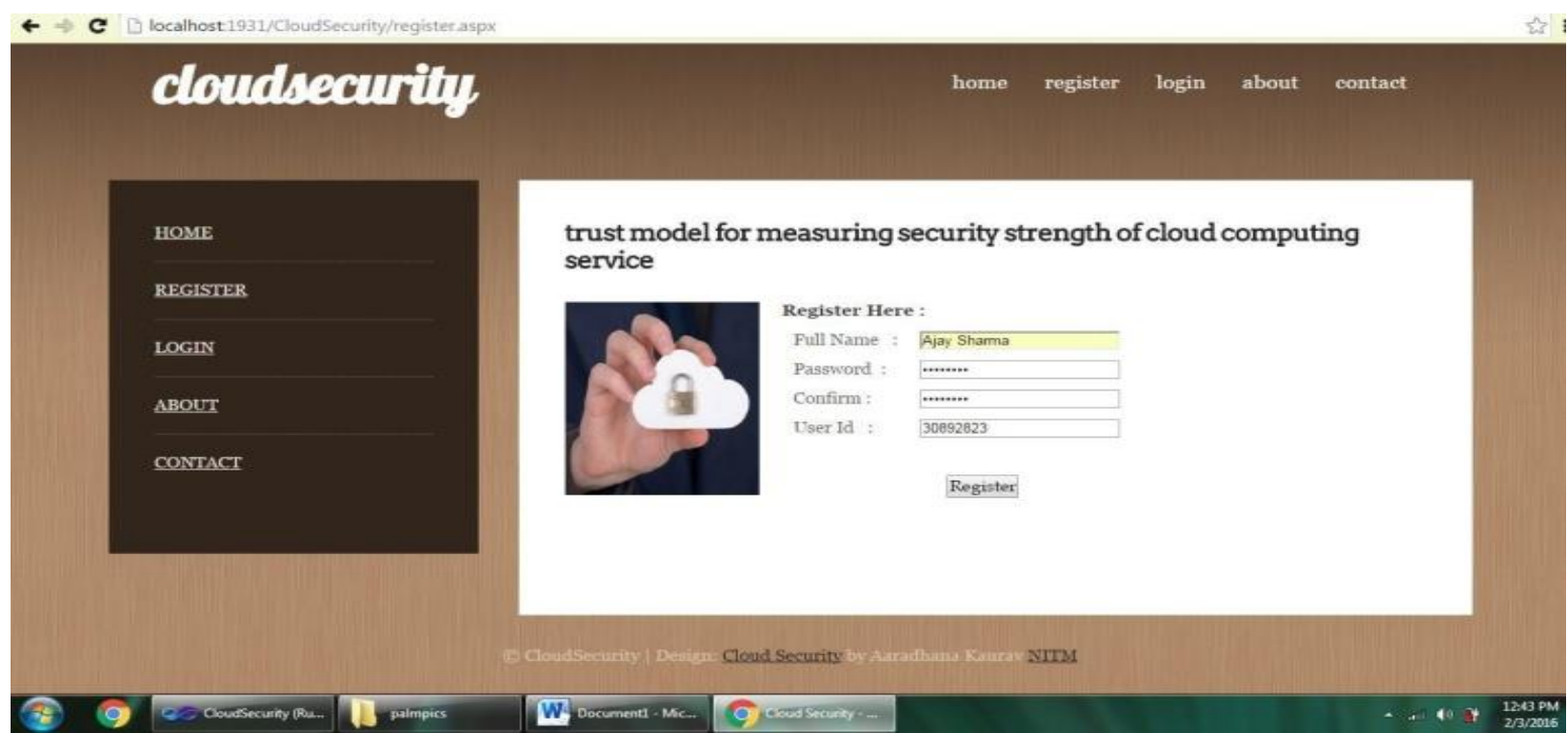

Fig. 4.2 Registration Page

You click on Registration button then registration shape is open and no of fields is shown for registration you fill the registration shape to test in the person. Fill entire name, password, confirm and user-id then click on check in button.

DOI Number: https://doi.org/10.30780/IJTRS.V06.I04.002

pg. 9 


\subsection{Registration System}

International Journal of Technical Research \& Science

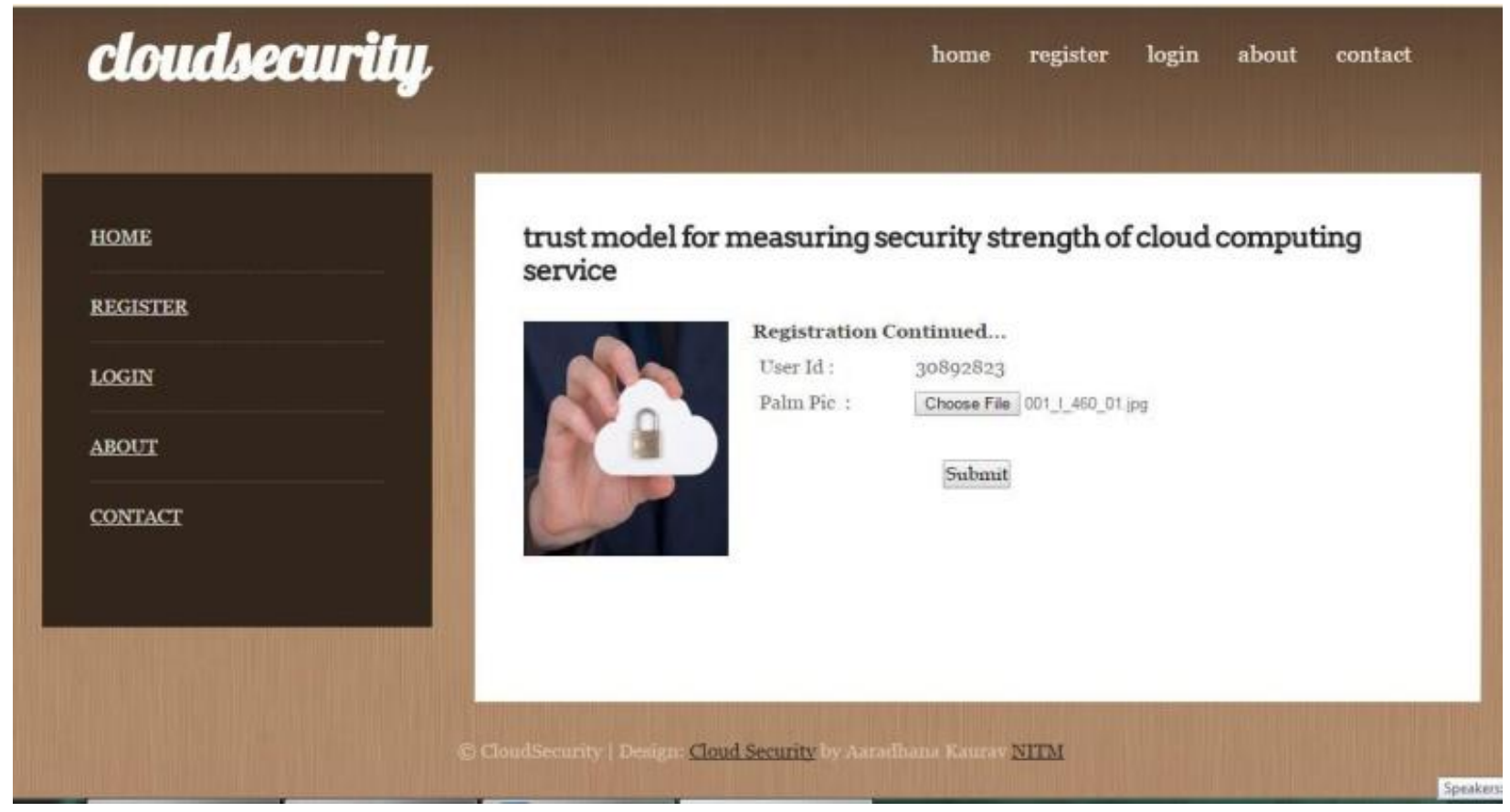

Fig. 4.3 Performing registration process

After clicking the registration button registration persevered form is opened and in this form palm $\%$ select out file preference is shown you pick out palm image register for customer authentication after deciding on the record click on put up button then your registration is a fulfillment.

\subsection{Login Form}

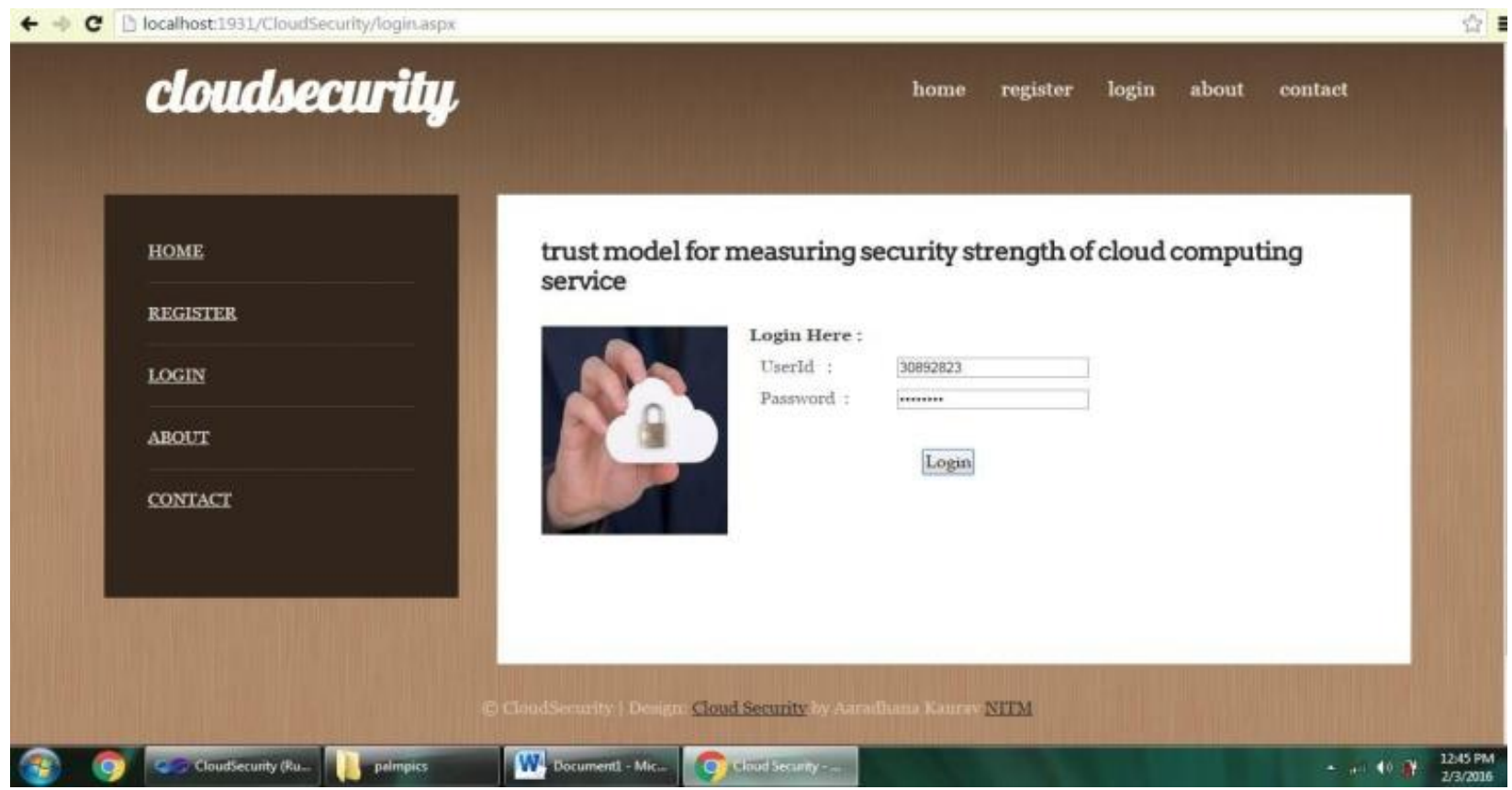

Fig 4.4 Login form

In home window form you click on login choice in menu of cloud safety then login form is opened and two fields are confirmed one is userid and 2nd one is password on the start you fill accurate facts in each fields and then enter login button then your form statistics is accurate then next form is opened.

DOI Number: https://doi.org/10.30780/IJTRS.V06.I04.002

pg. 10 


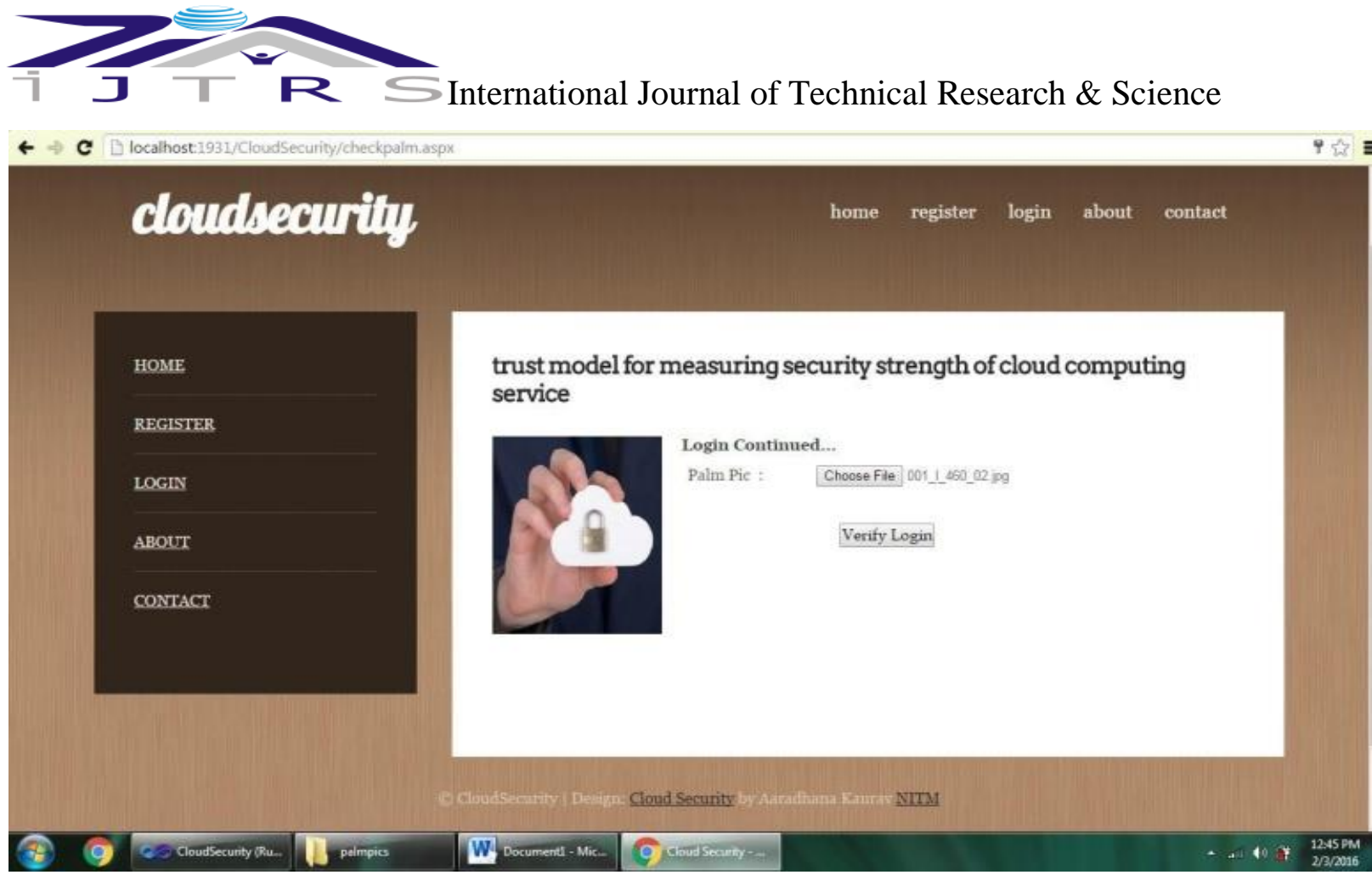

Fig. 4.5 Login Process continues

You continued next login form after first login form in this form choose palm pic and click verify login for complete successfully login then user home page is opened.

\subsection{User Home}

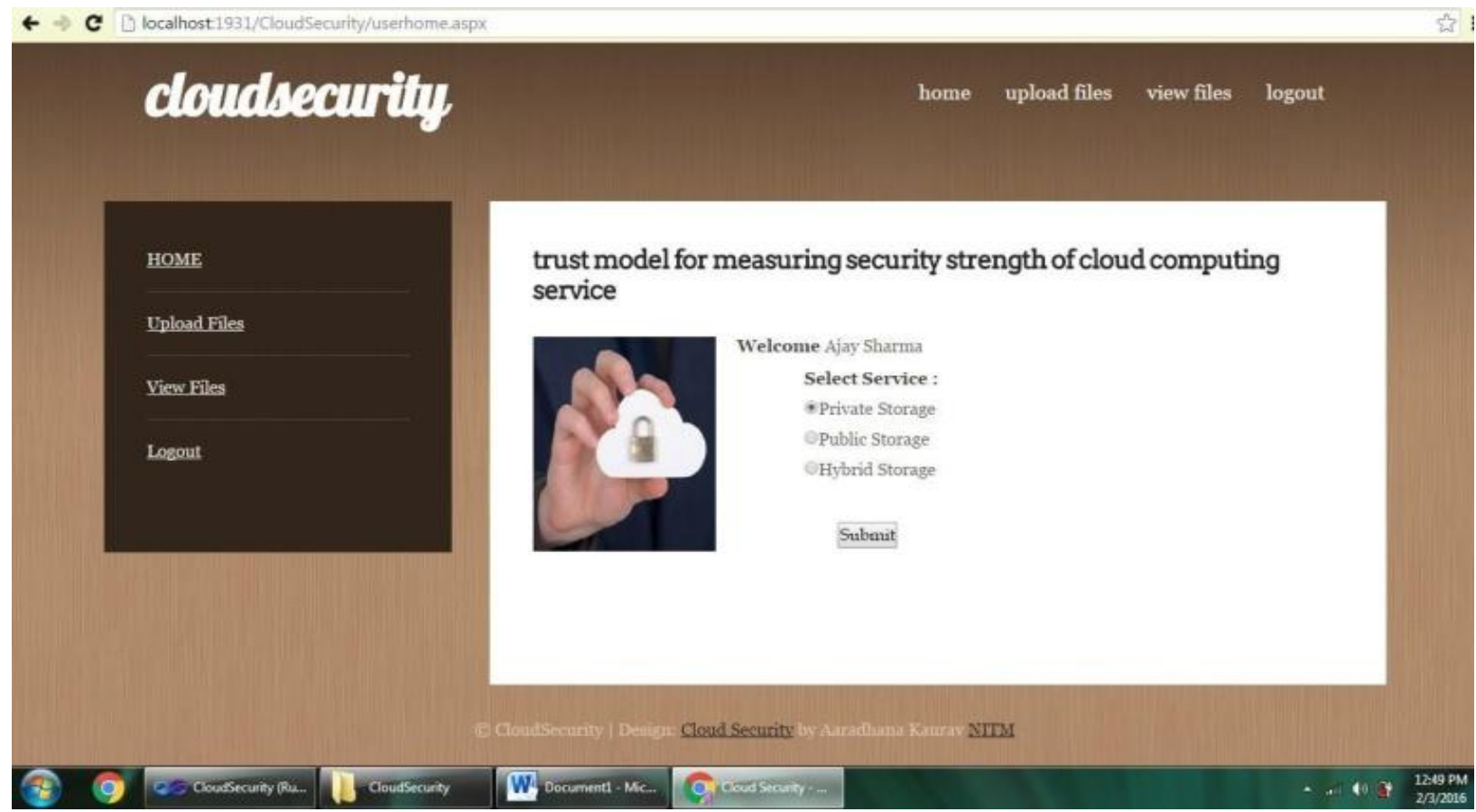

Fig. 4.6 User Home

Client touchdown page demonstrates no of fields, menu and unique various administrations for numerous utilizations like private stockpiling, open stockpiling and half of and half stockpiling. You pick out any kind of administrations as indicated by consumer necessity. You choose private stockpiling then personal form is opened this administrations utilize just for personal information.

DOI Number: https://doi.org/10.30780/IJTRS.V06.I04.002

pg. 11 


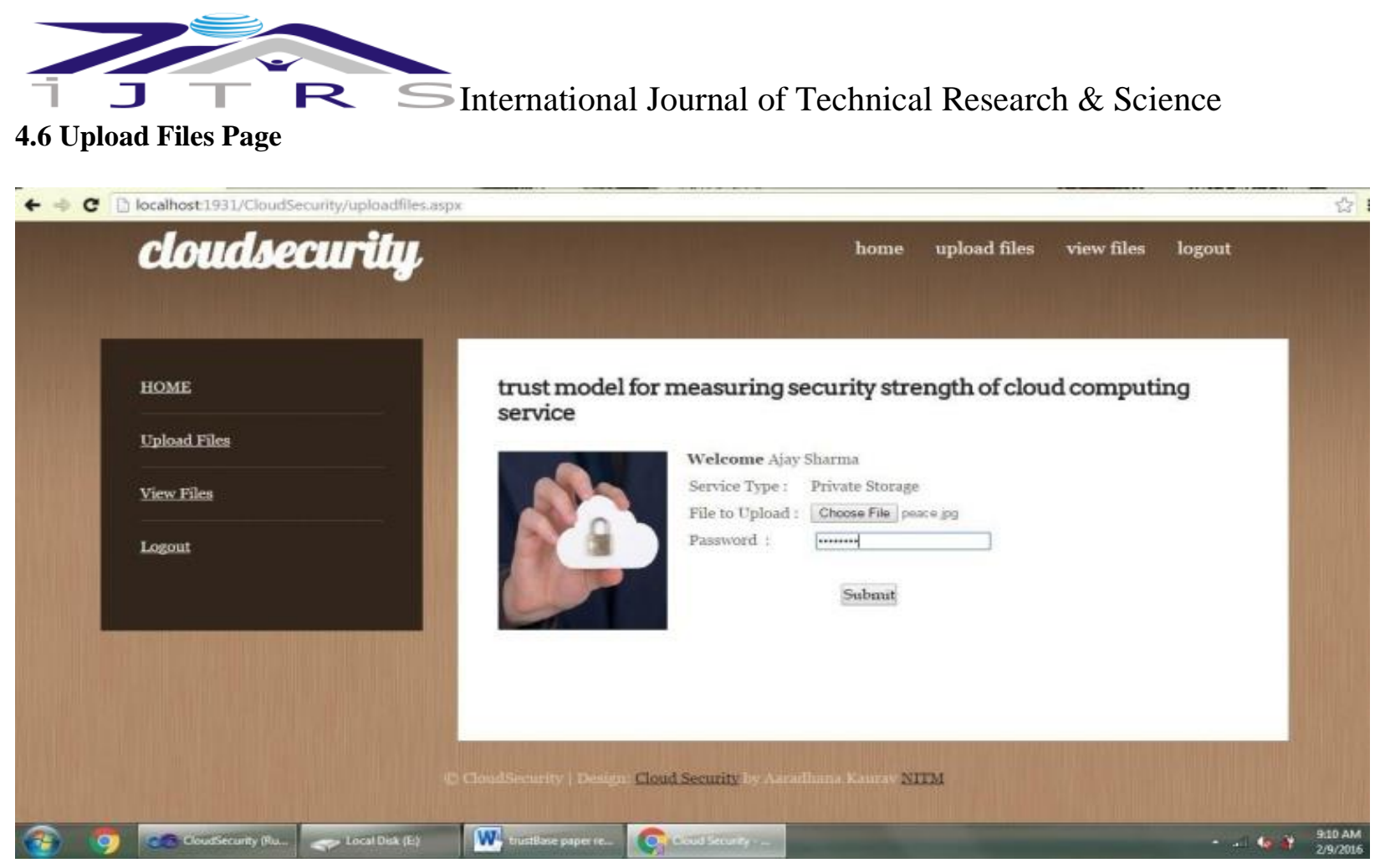

Fig. 4.7 Upload Files Page

In private storage services you choose private file and enter password and then click submit button. Password field use for private authentication that means this file access only private members who know the password.

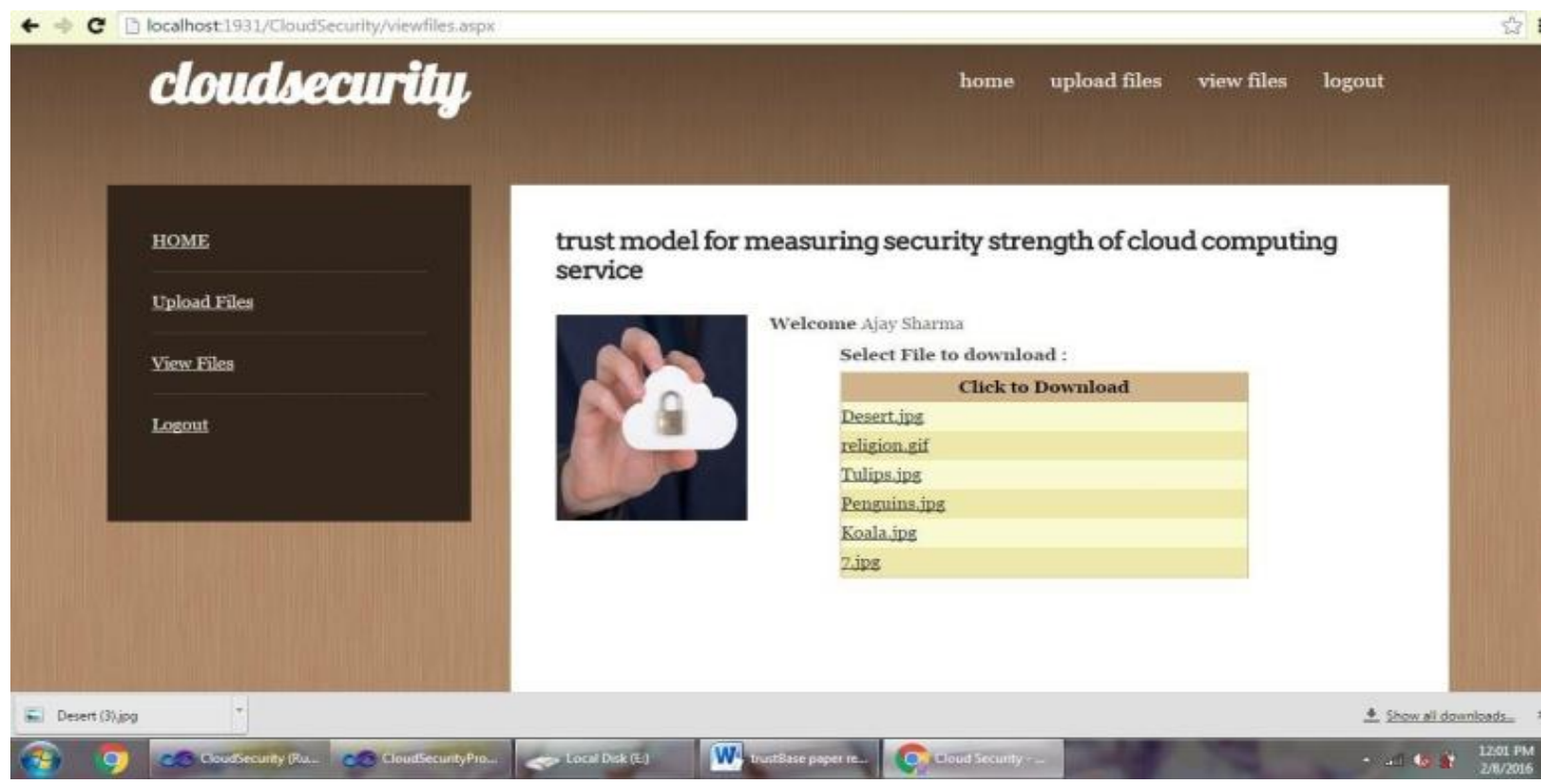

Fig. 4.8 View files

\subsection{View files}

This fig demonstrates the private record download possibility, choose a file to down load inside the wake of entering into the proper thriller key at that element click publish lure and download document. After download record download more possibility is appeared for downloading greater files.

Identical machine artwork for second and zero. 33 clients. Be that as it is able to, distinction demonstrates actually based totally absolutely totally on functionality administrations. 2nd consumer chooses Public garage offerings for switch report. Within the wake of choosing this switch body is opened then client switch record with any mystery key or verification as it supply record freely. This shows in each client and down load efficiently. 1/three customer 


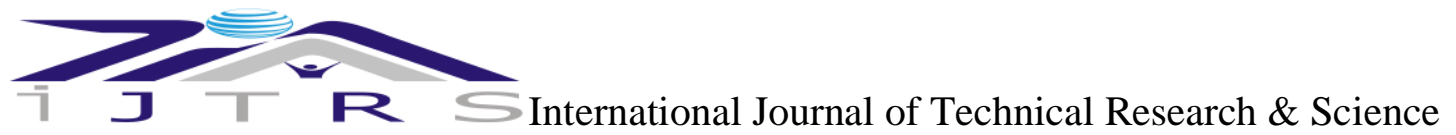

chooses Hybrid garage offerings for transfer document. inside the wake of choosing this switch body is opened then customer transfer report with choice of clients because it supply some confinement to attending to the file. This report downloaded by using the use of the usage of using surely decided on purchaser.

\section{CONCLUSION}

Drastically considered, the motive of this hypothesis has been to take a gander at the functionality outcomes to manufacture safety (in its broadest enjoy - elegance, respectability, accessibility) of virtualized situations out inside the open disbursed computing. Three regions - confided in figuring, dispensed computing and virtualization innovation fury fused into the repute quo mull over diploma. at the identical time as all of the 3 regions is currently progressing a forestall stop end result of full-size portions of employer and insightful vendors, believed processing had the benefit of being out and out determined and recorded in element. The protection stresses that hinder the extended reception of allocated computing prosper, so this hypothesis has centered on strolling up believe within the VM dispatch type out in a allotted computing scenario. In mindset of that, hints with apprehend to command over the trustworthiness of the host and honesty of the propelled VM photograph wrath figured to a constrained amount 3. A level self-governing believed nonexclusive digital device dispatch way of existence that would deal with the problems in the pointers (uprightness check of the VM have and of the propelled VM photo) end up illustrated in an iterative technique. Whilst the culture is considered as diploma impartial to the quantity the fabric allotted computing degree, it relies upon strongly at the usefulness gave via the usage of the use of the relied on Platform Module v1.2. Remembering the right aim to verify the implement ability of the manner of lifestyles and apprehend functionality zones of improvement, a point with the resource of thing associated utilization setup has been made in thoughts-set of the OpenStack allocated computing stage.

In this manner, the speculation has carried out its thing via arranging and executing a confided in dispatch life-style for nonexclusive VM in huge daytime allocated computing conditions, something which may be yield as a determination inside the path of an more and more comfy virtualized allotted computing scenario. The give up result fulfills maximum of the necessities portrayed in the hassle clarification of the proposition. Regardless of the truth that, the take a look at foundation for the evaluation of the manner of life execution and versatility is accurate now in an enhancement installation, thusly no such effects are open. In an increasingly more big experience, the advice ought to in popular be given as real with troubles inner virtualization situations out within the open allocated computing. The eventual results of the speculation may be yield as a number one commitment in the direction of an execution of a confided in nonexclusive VM dispatch tradition the use of an open supply allotted computing stage. Seemingly with the set up order don't forget and the extent pragmatist tradition plan, the execution time of the speculation has been progressively iterative and exploratory. From one thing of view, that could be a cease end result of the adolescent nation of the believed figuring programming stack (risky every to the amount programming splendid and with understand to assist for the winning permutations of Linux-based totally really strolling frameworks circulations).

Here Performing the load balancing for genetic algorithm for enhanced PSO in cloud computing. In this thesis, a task scheduled based on enhanced load balancing (ELBGA). ELBGA wont to minimize cost, minimize trip time, minimize execution time, minimize TRM, achieve load balancing between tasks and virtual machine, consider available resource and minimize the complexity in cloud computing environment. ELBGA improves the Reliability of cloud computing and good distribution of tasks onto resources compared to other algorithms. Founded the trip time ELBGA are able to do the simplest compared to other algorithms. additionally, proposed algorithm absorb account the load balancing when distributing tasks to available resources, tasks assign as earlier as possible, finished as earlier as possible and reschedule failure tasks. It are often used for any number of tasks and resources.

\section{REFERENCES}

[1] J. Somorovsky, M. Heiderich, M. Jensen, J. Schink, N. Gruschka, and L. Lo Iacono, "All your clouds are belong to us: security analysis of cloud management interfaces," in Proceedings of the 3rd ACM workshop on Cloud computing security workshop, CCSW '11, (New York, NY, USA), pp. 3-14, ACM, 2016.

[2] T. Ristenpart, E. Tromer, H. Shacham, and S. Savage, "Hey, you, get off of my cloud: exploring information leakage in third-party compute clouds," in Proceedings of the 16th ACM conference on Computer and communications security, CCS '09, (New York, NY, USA), pp. 199-212, ACM, 2018.

[3] D. Molnar and S. Schechter, "Self hosting vs .cloud hosting : Accounting for the security impact of hosting in the cloud," in Workshop of the economics of cloud security, pp. 1-18, 2010.

[4] Y. Chen, V. Paxson, and R. Katz, "The hybrex model for confidentiality and privacy in cloud computing," Technical Report UCB/EECS-2010-5, EECS Department, University of California, Berkeley, January 2015. 
J $\mathrm{R}$ S International Journal of Technical Research \& Science

[5] N. Santos, K. P. Gummadi, and R. Rodrigues, "Towards trusted cloud computing," in Proceedings of the 2009 conference on Hot topics in cloud computing, HotCloud'09, (Berkeley, CA, USA), USENIX Association, 2009.

[6] D. Kuhlmann, R. Landfermann, H. V. Ramasamy, M. Schunter, G. Ramunno, and D. Vernizzi, "An open trusted computing architecture - secure virtual machines enabling user-defined policy enforcement," Work, pp. $1-14,2006$.

[7] N. Pohlmann and H. Reimer, "Trusted computing - eine einfA 14 hrung," in Trusted Computing (N. Pohlmann and H. Reimer, eds.), pp. 3-12, Vieig+Teubner, 2008. 10.1007/978-3-8348-9452- 61.

[8] M. Nauman, S. Khan, X. Zhang, and J.-P. Seifert, "Beyond kernel-level integrity measurement: Enabling remote attestation for the android platform," in Trust and Trustworthy Computing (A. Acquisti, S. Smith, and A.-R. Sadeghi, eds.), vol. 6101 of Lecture Notes in Computer Science, pp. 1-15, Springer Berlin / Heidelberg, 2010. 10.1007/978-3-642-13869-01 